\title{
Dual-energy $C T$ quantitative parameters for evaluating Immunohistochemical biomarkers of invasive breast cancer
}

\author{
Xiaoxia Wang, Daihong Liu, Xiangfei Zeng, Shixi Jiang, Lan Li, Tao Yu and Jiuquan Zhang ${ }^{*}$ (D)
}

\begin{abstract}
Background: Estrogen receptor (ER), progesterone receptor (PR), human epidermal growth factor receptor 2 (HER2) and Ki67 are the most useful immunohistochemical biomarkers of invasive breast cancer. The purpose of this study is to investigate the possibility of quantitative parameters derived from dual-energy CT (DECT) to discriminate immunohistochemical biomarkers of invasive breast cancer.

Methods: This prospective study enrolled 120 patients with invasive breast cancer who underwent preoperative contrast-enhanced DECT for staging purposes from June 2019 to January 2020. DECT quantitative parameters, including normalized iodine concentration $(\mathrm{NIC})$, the slope of the spectral Hounsfield unit curve $\left(\lambda_{\mathrm{Hu}}\right)$, and the normalized effective atomic number $\left(n Z_{\text {eff }}\right.$ ), were obtained from reconstructed images. DECT quantitative parameters were compared with the expression status, and the correlations with the value of immunohistochemical biomarkers were evaluated. Inter-observer reproducibility analysis was performed to assess the measurement reproducibility of quantitative parameters. The diagnostic performance of the quantitative parameters was analyzed by receiver operating characteristic curve.
\end{abstract}

Results: The ER-negative group tended to display higher venous phase NIC and $\mathrm{nZ}$ eff compared with the ERpositive group (individually, $p=0.003,0.011$; area under the curve $[A \cup C]$ of $0.65,0.60$ ). The PR-negative group demonstrated higher arterial and venous phase NIC compared with the PR-positive group (individually, $p=0.022$, 0.005 ; AUC of $0.63,0.65)$. NIC was correlated negatively with the value of ER and PR expression $(r=-0.175 \sim-$ $0.265, p=0.002 \sim 0.042$ ). The HER2-positive group tended to display higher venous phase $\mathrm{nZ}$ eff than the HER2negative group ( $p=0.022$; AUC of 0.59). The Ki67 high-proliferation group demonstrated higher arterial phase, venous phase NIC and $\mathrm{nZ}$ eff than the Ki67 low-proliferation group $(p<0.001 \sim 0.005$; AUC of $0.67 \sim 0.75)$. Both the $\mathrm{NIC}$ and $\mathrm{nZ}$ eff were correlated positively with the value of Ki67 $(r=0.240 \sim 0.490, p<0.001 \sim 0.014)$.

Conclusions: $\mathrm{NIC}$ and $\mathrm{nZ}$ eff derived from DECT could be used to discriminate expression status and may associate with the value of immunohistochemical biomarkers of invasive breast cancer.

Keywords: Dual-energy CT, Quantitative parameters, Invasive breast cancer, Immunohistochemical biomarkers

\footnotetext{
* Correspondence: zhangja_radiol@foxmail.com

Department of Radiology, Chongqing University Cancer Hospital, School of Medicine, Chongqing University, Chongqing 400030, People's Republic of China
}

(c) The Author(s). 2020 Open Access This article is licensed under a Creative Commons Attribution 4.0 International License, which permits use, sharing, adaptation, distribution and reproduction in any medium or format, as long as you give appropriate credit to the original author(s) and the source, provide a link to the Creative Commons licence, and indicate if changes were made. The images or other third party material in this article are included in the article's Creative Commons licence, unless indicated otherwise in a credit line to the material. If material is not included in the article's Creative Commons licence and your intended use is not permitted by statutory regulation or exceeds the permitted use, you will need to obtain permission directly from the copyright holder. To view a copy of this licence, visit http://creativecommons.org/licenses/by/4.0/ The Creative Commons Public Domain Dedication waiver (http://creativecommons.org/publicdomain/zero/1.0/) applies to the data made available in this article, unless otherwise stated in a credit line to the data. 


\section{Introduction}

Breast cancer is a heterogeneous tumor that represents the accumulation of complex genetic alterations and can be divided into different subtypes according to the receptor status. The most useful receptors in breast cancer cells, which determine therapy strategy, are estrogen receptor (ER), progesterone receptor (PR) and human epidermal growth factor receptor 2 (HER2). ER-positive and PRpositive cases have a lower risk of mortality than ERnegative and/or PR-negative cases, while HER2-positive breast cancers tend to be more aggressive and have a poorer prognosis than HER2-negative breast cancer $[1,2]$. Several studies [3, 4] have proved the prognostic value of the Ki67 index in patients with breast cancer. Preoperative phenotyping of breast cancer is critical because it may predict the response to neoadjuvant chemotherapy and provide optimized strategies for patient-tailored therapy.

Currently, multiple quantitative parameters derived from dual-energy CT (DECT), including normalized iodine concentration (NIC), the slope of the spectral Hounsfield unit (HU) curve $\left(\lambda_{\mathrm{Hu}}\right.$, in Hounsfield unit per kiloelectron-volt), and the normalized effective atomic number ( $\mathrm{n} \mathrm{Z}_{\mathrm{eff}}$ ), have attracted wide research interest in tumors, such as head [5, $6]$, lung [7-9], liver [10, 11], kidney [12, 13], and other organ imaging studies [14-16]. DECT has been proven to be an effective method to evaluate neoangiogenesis and has been increasingly applied in tumor detection and characterization [17]. Breast cancer development typically results in angiogenesis, which increases the formation of small vessels in and near the tumor $[18,19]$.

Clinicians usually use contrast-enhanced CT scans of the thorax for the evaluation of potential lung metastasis or underlying lung tuberculosis [20]. However, routine thorax CT is unable to characterize the primary breast tumor precisely due to its relatively low resolution of soft tissue, limited imaging mode and qualitative parameters [21]. A few studies using iodine-based material decomposition images have shown that the iodine concentration was significantly higher in tumors than in normal breast tissue and pectoral muscle [22]. A recent study [23] demonstrated the feasibility of DECT for locoregional staging of breast cancer, and the iodine concentration of invasive non-special carcinoma was higher than that of ductal carcinoma in situ and benign tumors. Therefore, we attempted to correlate the quantitative parameters derived from DECT with immunohistochemical factors of breast cancer.

The purpose of this study was to investigate the possibility of quantitative parameters derived from DECT to discriminate immunohistochemical biomarkers of invasive breast cancer.

\section{Materials and methods}

\section{Patient characteristics}

This prospective study was approved by the institutional review board, and written informed consent was collected from every participant. From June 2019 to February 2020, 120 consecutive women were enrolled, with a median age of $53.3 \pm 9.9$ years (range, $32 \sim 87$ years). Ninety-seven women who were pathological diagnosed breast cancer, were instructed to undergo DECT for evaluation of potential lung metastasis, while twenty-three women who were suspected of having breast cancer by on mammography or/and ultrasonography or/and MRI, were instructed to undergo DECT for evaluation of lung tuberculosis or other inflammation. Finally, the lesions were confirmed by histopathology as invasive breast cancer after the examination. Inclusion criteria included a first diagnosis of breast cancer, breast masses with a shortest diameter larger than $1 \mathrm{~cm}$ and visibility on DECT-enhanced images, women who had not undergone biopsy of the breast mass within 1 week before the initial CT examination, and women who had no history of chemotherapy or radiation therapy in the breast space. The exclusion criteria for DECT were based on the clinical guidelines of contrast-enhanced CT at our institution: impaired kidney function (glomerular filtration rate $<30 \mathrm{ml} / \mathrm{min}$ ), severe contrast media allergy, and inability to give informed consent for the CT examination. Patient demographics and histopathological diagnosis data for each patient were extracted from the hospital's electronic medical records.

We reviewed the immunohistochemistry diagnosis data from the hospital's electronic medical records. The immunohistochemical results of ER, PR and HER2 were classified as positive or negative [24]. ER or PR positivity was defined as $\geq 1 \%$ nuclear immunostaining. HER2 overexpression was considered in $3+$ immunohistochemical staining or $2+$ immunohistochemical staining and HER2 gene amplification in silver-stained in situ hybridization. The Ki-67 index was assessed as the percentage of immunoreactive tumor cells, and a cut-off value of $20 \%$ was used to define the low- and highproliferation tumor groups [25].

\section{DECT image acquisition}

Image data were acquired on a 2.5 generation dualsource CT unit (SOMATOM Drive, Siemens Healthineers, Forchheim, Germany) in dual-energy mode through two $\mathrm{X}$-ray tubes with different $\mathrm{kV}$ tube voltages (tube A, $100 \mathrm{kV}$; tube B, Sn $140 \mathrm{kV}$ ) using a tin filter for the high-voltage tube. Automatic exposure control (CARE Dose 4D, Siemens Healthineers) was used in all scans. The settings for the scanners were as follows: collimation, $64 \times 0.6 \mathrm{~mm}$; rotation time, $0.28 \mathrm{~s}$; pitch, 0.55 ; reference tube current time product, $71 \mathrm{mAs}$ for the $100-\mathrm{kVp}$ tube and $60 \mathrm{mAs}$ for the Sn140-kVp tube; reformatted section thickness, $1.5 \mathrm{~mm}$; reformatted section increment, $1.5 \mathrm{~mm}$.

All patients were scanned craniocaudally in the supine position with the bilateral arms elevated in close contact 
with the head. The whole chest was scanned from the superior aperture of the thorax to the inferior edge of the costophrenic angle during a deep-inspiratory breath hold, which covered the breast and axillary area. For contrast-enhanced scanning, an iodinated nonionic contrast media (Ioversol, $320 \mathrm{mg} / \mathrm{ml}$ iodine, HENGRUI Medicine, Jiangsu, China) was administered through the right or left ulnar vein by a dual-head injector. The dosage was $1.5 \mathrm{ml} / \mathrm{kg}$ with a flow rate of $2.5 \mathrm{ml} / \mathrm{sec}$, followed by a bolus injection of $30 \mathrm{ml}$ of saline given at the same flow rate. The side of the ulnar vein that was injected was selected to be contralateral to the suspected breast lesion to avoid a beam hardening artifact of the axillary vein. After the injection, the arterial phase scans were started using a bolus-tracking technique with a threshold of 100 $\mathrm{HU}$ in the descending aorta and an additional delay of 10 s. The scan delay time for the venous phase scanning was $25 \mathrm{~s}$ after the end of the arterial phase scanning.

\section{DECT image analysis}

DECT data were analyzed by using viewer software on a syngo.via workstation (syngo.via VB20A, Dual Energy, Siemens Healthineers, Forchheim, Germany). Standard linear-blended images were reconstructed by applying a blending factor of 0.5 (M_0.5; $50 \%$ of the low $\mathrm{kV}$ and $50 \%$ of the high-kV spectrum). DECT quantitative parameters were measured by two radiologists (X.X.W, with 6 years of experience in breast and chest diagnostic imaging, and X.F.Z, with 2 years of experience in postreconstruction imaging) who were blinded to the immunohistochemical results of invasive breast cancer, by placing a circular region of interest, $1 \mathrm{~cm}^{2}$ in size, excluding any area of obviously gross necrosis, calcification or large vessels. Quantitative parameters, including the iodine concentration (in milligrams per cubed centimeter) and the effective atomic number, were divided by the iodine concentration and effective atomic number of aorta, respectively, to obtain the normalized iodine concentration (NIC) and normalized effective atomic number $\left(n Z_{\text {eff }}\right)$. The slope of the spectral Hounsfield unit curve $\left(\lambda_{\mathrm{Hu}}\right.$ in Hounsfield unit per kiloelectron-volt) was calculated as follows [26]:

$$
\mathrm{Hu}=(\mathrm{HU} 40 \mathrm{keV}-\mathrm{HU} 70 \mathrm{keV}) / 30 \mathrm{keV}
$$

\section{Statistical analysis}

Statistical analyses were performed using commercially available statistical software (IBM SPSS Statistics, version 22.0). Inter-observer agreement was calculated with quadratic weighted Cohen's kappa coefficients, with values of $\geq 0.81$ indicating excellent, $0.61 \sim 0.80$ substantial, $0.41 \sim 0.60$ moderate, $0.21 \sim 0.40$ fair, and $\leq 0.20$ poor agreement. Quantitative variables are expressed as the mean \pm standard deviation. In the univariable analyses, continuous data were compared using the independent sample $t$ test. Receiver operating characteristic (ROC) curve analysis was used to evaluate the diagnostic capacity of DECT quantitative parameters. The sensitivity, specificity, and accuracy with $95 \%$ confidence intervals were calculated, and the optimal threshold was determined by the Youden index. The Spearman correlation test was used to correlate DECT quantitative parameters with the value of immunohistochemical biomarkers in invasive breast cancer. The degree of correlation was classified as a direct correlation or an inverse correlation depending on whether $r$ was a positive value or a negative value, respectively. The level of significance was defined as $p<0.05$.

\section{Results}

\section{Patient characteristics}

Ultimately, 120 participants (53.3 \pm 9.9 years; range, $32 \sim$ 87 years) who had invasive breast cancer with DECT images were included in our study. Another 120 participants were excluded because they had no/incomplete pathological information $(n=23)$, received a mass biopsy within 1 week before CT scanning $(n=33)$, had benign tumors $(n=22)$, had a breast mass invisible/shortest diameter $<1 \mathrm{~cm}(n=12)$, had a breast mass exceeding the field of view due to obesity $(n=7)$, and had received neoadjuvant chemotherapy before CT scanning $(n=23)$. Demographic characteristics and the immunohistochemical biomarkers distribution in our study population are provided in Table 1.

The mean diameter of total tumor sizes was $2.96 \pm 1.38$ $\mathrm{cm}$, and tumors were larger than $2 \mathrm{~cm}$ in 88 cases and 2 $\mathrm{cm}$ or smaller in 32 cases. The 120 cases of invasive breast cancer were confidently classified as ER-positive $(n=86)$ vs ER-negative $(n=34)$, PR-positive $(n=53)$ vs PRnegative $(n=67)$, HER2-positive $(n=47)$ vs HER2negative $(n=73)$, and Ki67 low-proliferation $(n=70)$ vs Ki67 high-proliferation $(n=50)$. Representative iodine overlay images, Z effective maps, graphs of spectra Hounsfield unit curves and immunohistochemical staining for patient with PR-negative and PR-positive (Fig. 1), ERnegative and ER-positive (Fig. 2) HER2-negative and HERpositive (Fig. 3), Ki67 high-proliferation and Ki67 lowproliferation (Fig. 4) are illustrated.

The mean CT dose index volume was $15.43 \pm 4.89$ $\mathrm{mGy}$, and the mean dose length product was $470.22 \pm$ $129.83 \mathrm{mGy} \mathrm{cm}$ for each woman. Summary statistics of DECT quantitative parameters among immunohistochemical biomarkers of invasive breast cancer are presented in Table 2 and Fig. 5. Inter-observer agreement for the evaluation of DECT quantitative parameters ranged between substantial and excellent, with kappa values of $0.740 \sim 0.938$. The area under the ROC curve 
Table 1 Summary of Demographic Characteristics

\begin{tabular}{|c|c|}
\hline Characteristic & Number \\
\hline No. of Participants & 120 \\
\hline Age, Mean $\pm S D$, years (Range) & $53.3 \pm 9.9$ years (range, $32 \sim 87$ years) \\
\hline \multicolumn{2}{|l|}{ Menstruation State } \\
\hline Premenopausal women & 34 \\
\hline Postmenopausal women & 69 \\
\hline Perimenopausal women & 17 \\
\hline Tumor size, Mean $\pm \mathrm{SD}, \mathrm{cm}$ & $2.96 \pm 1.38 \mathrm{~cm}$ \\
\hline \multicolumn{2}{|l|}{ Tumor size } \\
\hline$\leq 2 \mathrm{~cm}$ & 32 \\
\hline$>2 \mathrm{~cm}$ & 88 \\
\hline \multicolumn{2}{|l|}{ ER } \\
\hline positive & 86 \\
\hline negative & 34 \\
\hline \multicolumn{2}{|l|}{$P R$} \\
\hline positive & 53 \\
\hline negative & 67 \\
\hline \multicolumn{2}{|l|}{ HER2 } \\
\hline positive & 47 \\
\hline negative & 73 \\
\hline \multicolumn{2}{|l|}{ Ki67 } \\
\hline low-proliferation & 70 \\
\hline high-proliferation & 50 \\
\hline
\end{tabular}

Note. $S D$ standard deviation, $E R$ estrogen receptor, $P R$ progesterone receptor, $H E R 2$ human epidermal growth factor receptor 2
(AUC), sensitivity, specificity and accuracy with 95\% confidence intervals for the quantitative parameter thresholds are summarized in Table 3. Correlations of DECT quantitative parameters with the values of immunohistochemical biomarkers in invasive breast cancer are summarized in Table 4.

\section{Associations between DECT quantitative parameters and hormone receptors \\ ER-negative tumors showed significantly higher venous phase NIC and venous phase $\mathrm{nZ}_{\mathrm{eff}}(p=0.003$ and 0.011 , respectively) than ER-positive tumors, with areas under the curve (AUCs) of 0.65 and 0.60 , sensitivities of 88.4 and $70.9 \%$, specificities of 41.2 and $50 \%$, and accuracies of 75 and $65 \%$. The value of ER expression was corre- lated negatively with the venous phase NIC in invasive breast cancer $(r=-0.265, p=0.002)$. Likewise, PR- negative tumors showed significantly higher arterial and venous phase NIC than PR-positive tumors $(p=0.022$ and 0.005 , respectively), with AUCs of 0.63 and 0.65 , sensitivities of 75.5 and $62.3 \%$, specificities of 50.7 and $62.7 \%$, and accuracies of 61.7 and $62.5 \%$. The value of PR expression was correlated negatively with the arterial and venous phase NIC in invasive breast cancer $(r=-$ $0.175,-0.239, p=0.042,0.005$, respectively).}

\section{Associations between DECT quantitative parameters and HER2 receptor}

HER2-positive tumors showed significantly higher venous phase $\mathrm{nZ}_{\text {eff }}(p=0.022)$ than HER2-negative tumors, with an AUC of 0.59 , a sensitivity of $70.2 \%$, a specificity of $53.4 \%$, and an accuracy of $60 \%$. However, no obvious

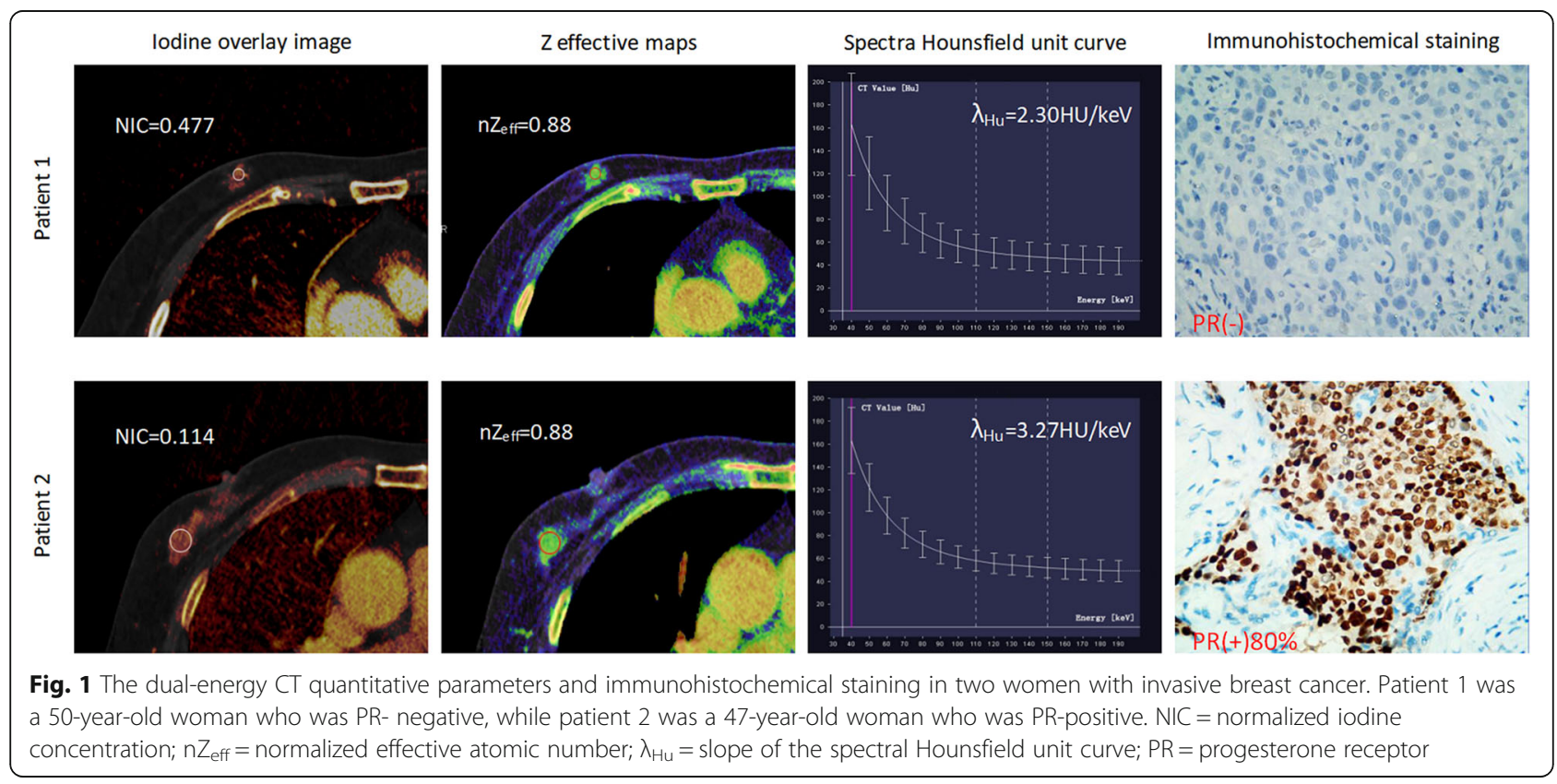




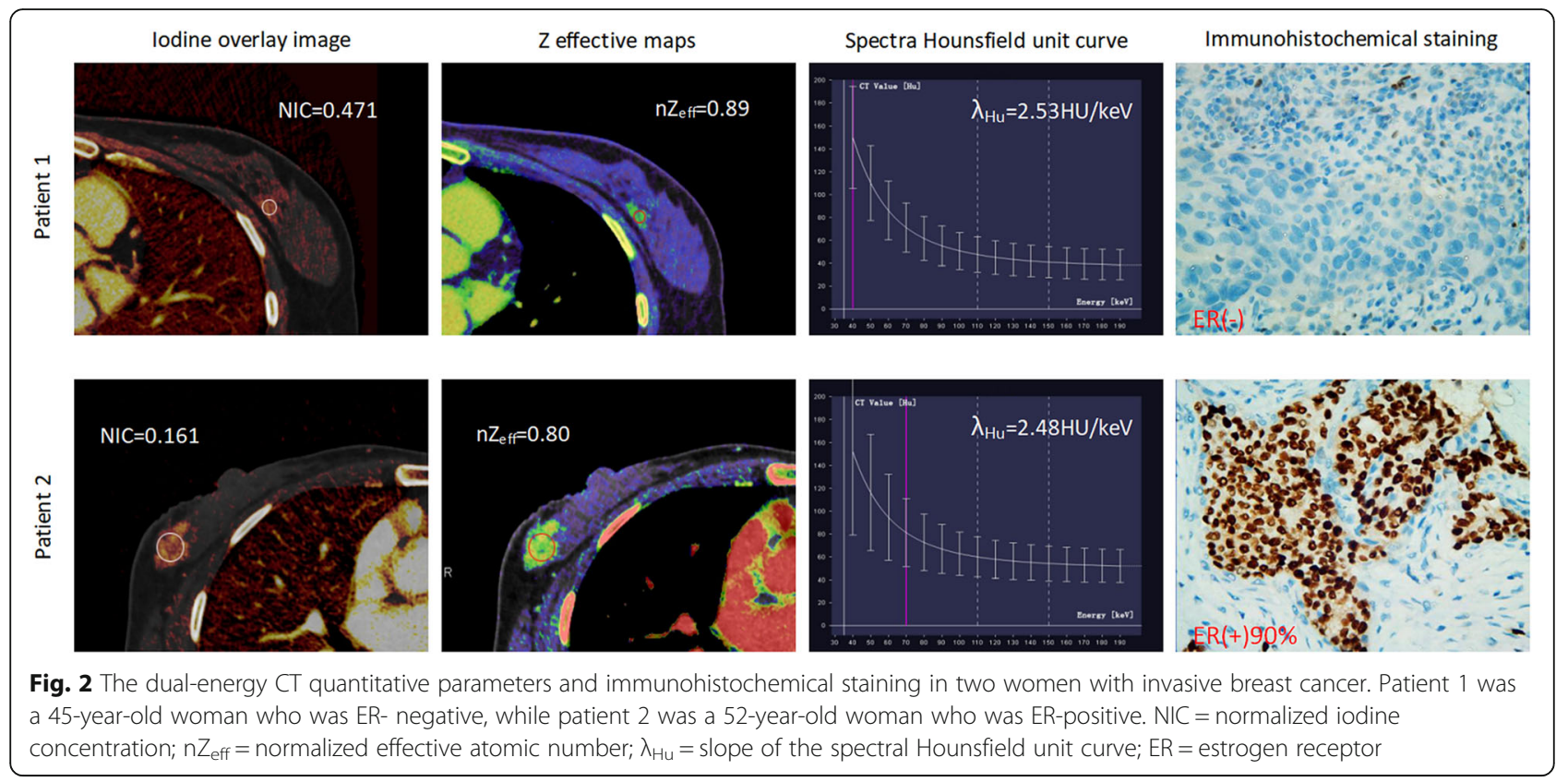

correlation ( $r=0.112, p=0.194)$ was observed, and no significant differences in arterial phase NIC, $\mathrm{nZ}_{\text {eff }}$ and $\lambda_{\mathrm{Hu}}$, venous phase NIC and $\lambda_{\mathrm{Hu}}$ were observed between HER2-positive and HER2-negative tumors $(p=0.077$ $0.850)$.

\section{Associations between DECT quantitative parameters and Ki67 value}

Regarding Ki-67 expression, the Ki-67 high-proliferation group demonstrated significantly higher arterial and venous phase NIC, $\mathrm{nZ}_{\text {eff }}$ compared with the Ki67 low- proliferation group $(p<0.001 \sim 0.005)$, with AUCs of $0.67 \sim 0.75$, sensitivities of $65.7 \sim 88.6 \%$, specificities of $50.0 \% \sim 62.0 \%$, and accuracies of $64.2 \% \sim 73.3 \%$. The value of Ki67 expression was correlated positively with the NIC and $\mathrm{nZ}_{\text {eff }}$ values in invasive breast cancer $(r=$ $0.240 \sim 0.490, p=0.014 \sim<0.001)$.

\section{Discussion}

Our results showed that quantitative parameters derived from DECT could be used to discriminate immunohistochemical biomarkers of invasive breast cancer. NIC and
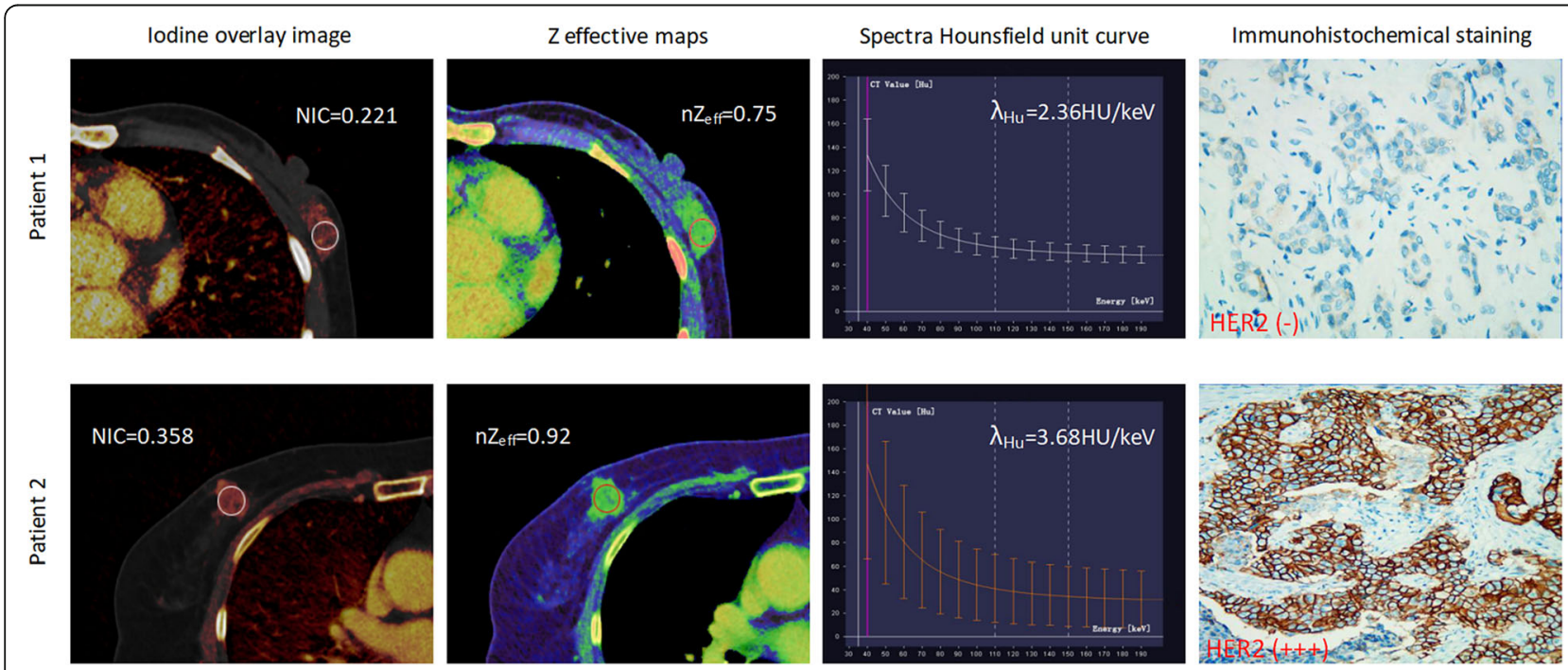

Fig. 3 The dual-energy CT quantitative parameters and immunohistochemical staining in two women with invasive breast cancer. Patient 1 was a 56-year-old woman who was HER2-negative, while patient 2 was a 50-year-old woman who was HER2-positive. NIC = normalized iodine concentration; $\mathrm{nZ}_{\mathrm{eff}}=$ normalized effective atomic number; $\lambda_{\mathrm{Hu}}=$ slope of the spectral Hounsfield unit curve; HER2 = human epidermal growth factor receptor 2 

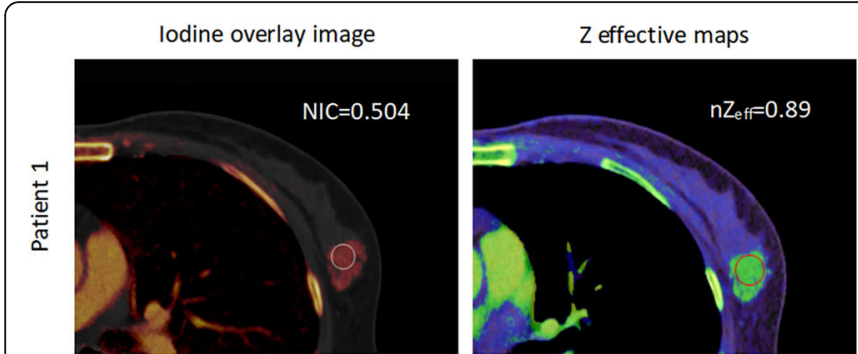

Spectra Hounsfield unit curve

Immunohistochemical staining
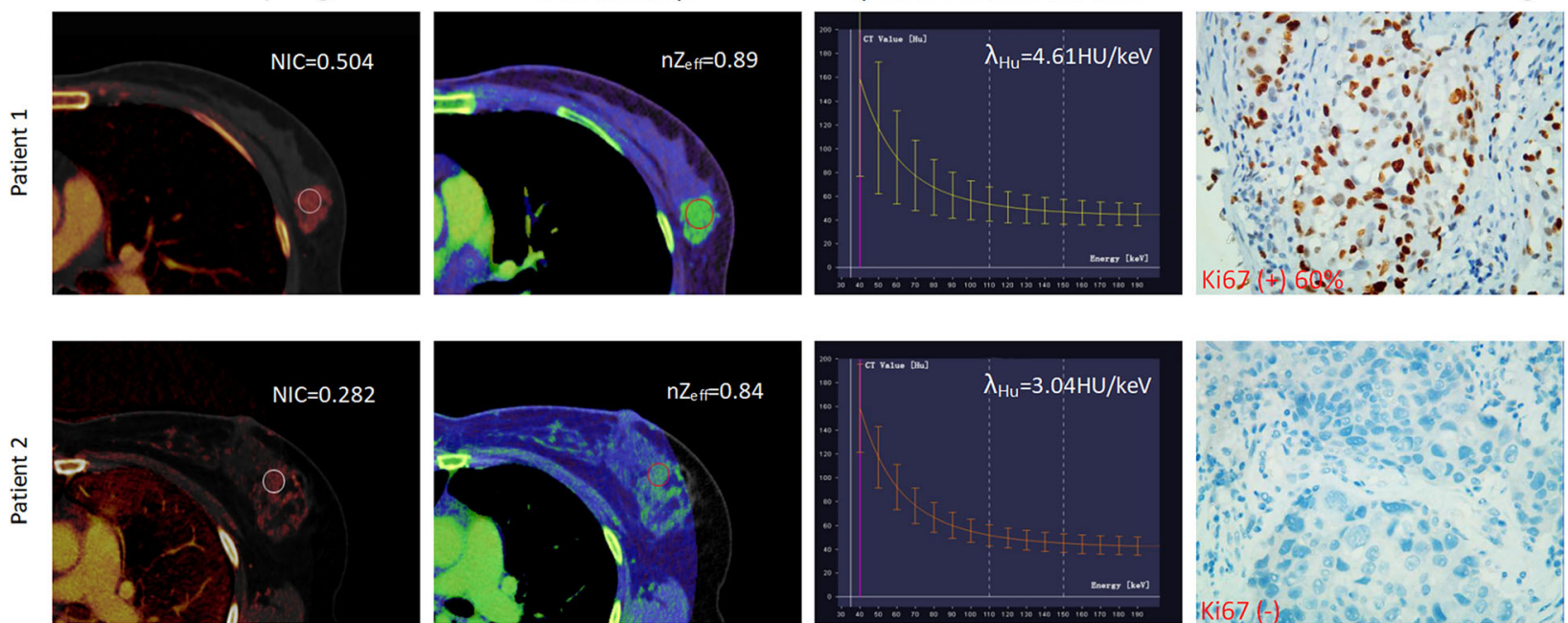

Fig. 4 The dual-energy CT quantitative parameters and immunohistochemical staining in two women with invasive breast cancer. Patient 1 was a 51-year-old woman who was Ki67 high-proliferation, while patient 2 was a 46-year-old woman who was Ki67 low-proliferation. NIC $=$ normalized iodine concentration; $n Z_{\text {eff }}=$ normalized effective atomic number; $\lambda_{\mathrm{Hu}}=$ slope of the spectral Hounsfield unit curve

$\mathrm{nZ}_{\mathrm{eff}}$ values were associated with $\mathrm{ER}$ and Ki67 expression statuses, while NIC was associated with PR expression status, and the $\mathrm{nZ}_{\mathrm{eff}}$ value was an indicator of HER2 in invasive breast cancer. The NIC was negatively correlated with the values of ER and PR expression, while the $\mathrm{NIC}$ and $n Z_{\text {eff }}$ were positively correlated with the value of $\mathrm{Ki}-67$ expression.

The hormone receptors ER and PR are known to be important prognostic factors and predictive biomarkers of endocrine therapy response to breast cancer. In this study, the ER-negative group tended to display higher venous phase NIC and venous phase $\mathrm{nZ}_{\text {eff }}$ compared with the ER-positive group, while the PR-negative group demonstrated significantly higher arterial and venous phase NIC compared with the PR-positive group. The NIC was correlated negatively with the values of ER and PR expression. A study [27] on the application of lowdose perfusion CT in breast cancers showed that the perfusion was significantly higher while the time to peak was significantly shorter in ER- and PR-negative breast cancers than in the positive group. This may be related to the fact that the velocity and amount of tumor vessels reflect the behavior and prognosis of the tumor. Previous research [28] has demonstrated that ER expression is associated with inhibition of angiogenesis, which would reduce perfusion. PR is generally regarded as a marker of a functional ER pathway because the transcription of the PR gene is enhanced and maintained by estrogen [29]. The distribution of iodine in the tissue is strongly related to local blood volume and vascular density [17]. Therefore, NIC may reflect the expression of ER and PR through breast cancer angiogenesis.
Breast cancer with HER2 overexpression is characterized by increased cell proliferation and angiogenesis, which is associated with metastasis progression and poor prognosis [30]. In our study, the HER2-positive group tended to display higher venous phase $\mathrm{nZ}_{\text {eff }}$ compared with the HER2-negative group. Material decomposition images can be used to estimate the concentration of a given material (i.e., water, gadolinium or iodine) with a given atomic mass in the region of interest, thus potentially distinguishing different tissues [31]. $\mathrm{nZ}_{\text {eff }}$ is a quantitative indicator of the compound atom of a compound or a mixture of various materials. A previous study [32] demonstrated that DECT allowed the confident evaluation of silicone within breast soft tissues in reconstructed images. However, the clinical significance of $\mathrm{nZ}_{\text {eff }}$ applied to tumors is not clear. The HER2-positive group had higher venous phase NIC than the HER2negative group, however, these differences were not significant.

Ki67 is a biomarker considered to represent the state of tumor proliferation; a high Ki67 index is associated with adverse clinical outcomes in breast cancer patients [33]. In our study, the Ki67-positive group demonstrated significantly higher arterial phase, venous phase NIC and $\mathrm{nZ}$ eff compared with the Ki67-negative group. Both the $\mathrm{NIC}$ and $\mathrm{nZ}$ eff were correlated positively with the value of Ki67 expression. Some previous studies [34, 35] have found that the NIC values were positively correlated with Ki67 expression in rectal and gastric cancer. One possible explanation for these findings may be that highproliferating tumors are more heterogeneous, such as breast cancer, and are characterized by complex changes, 


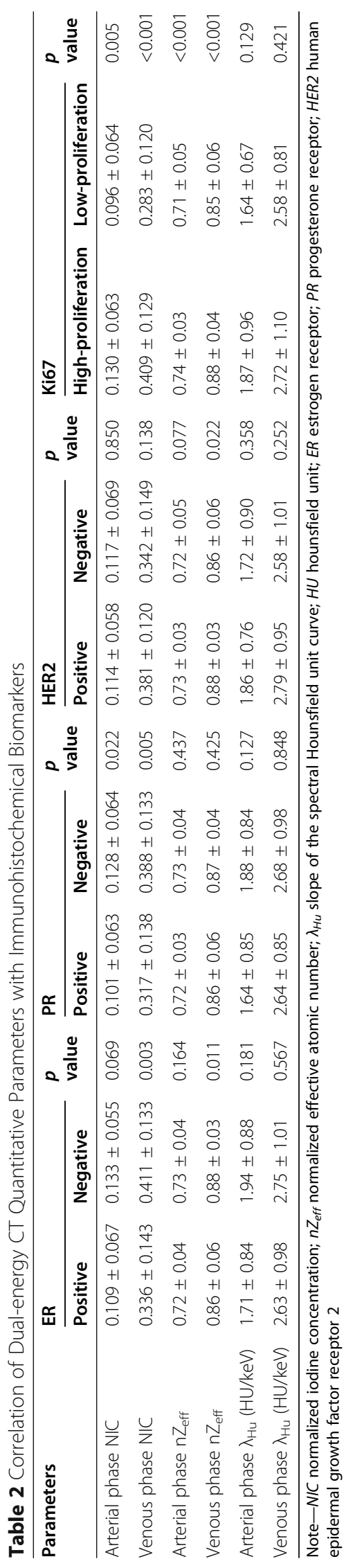




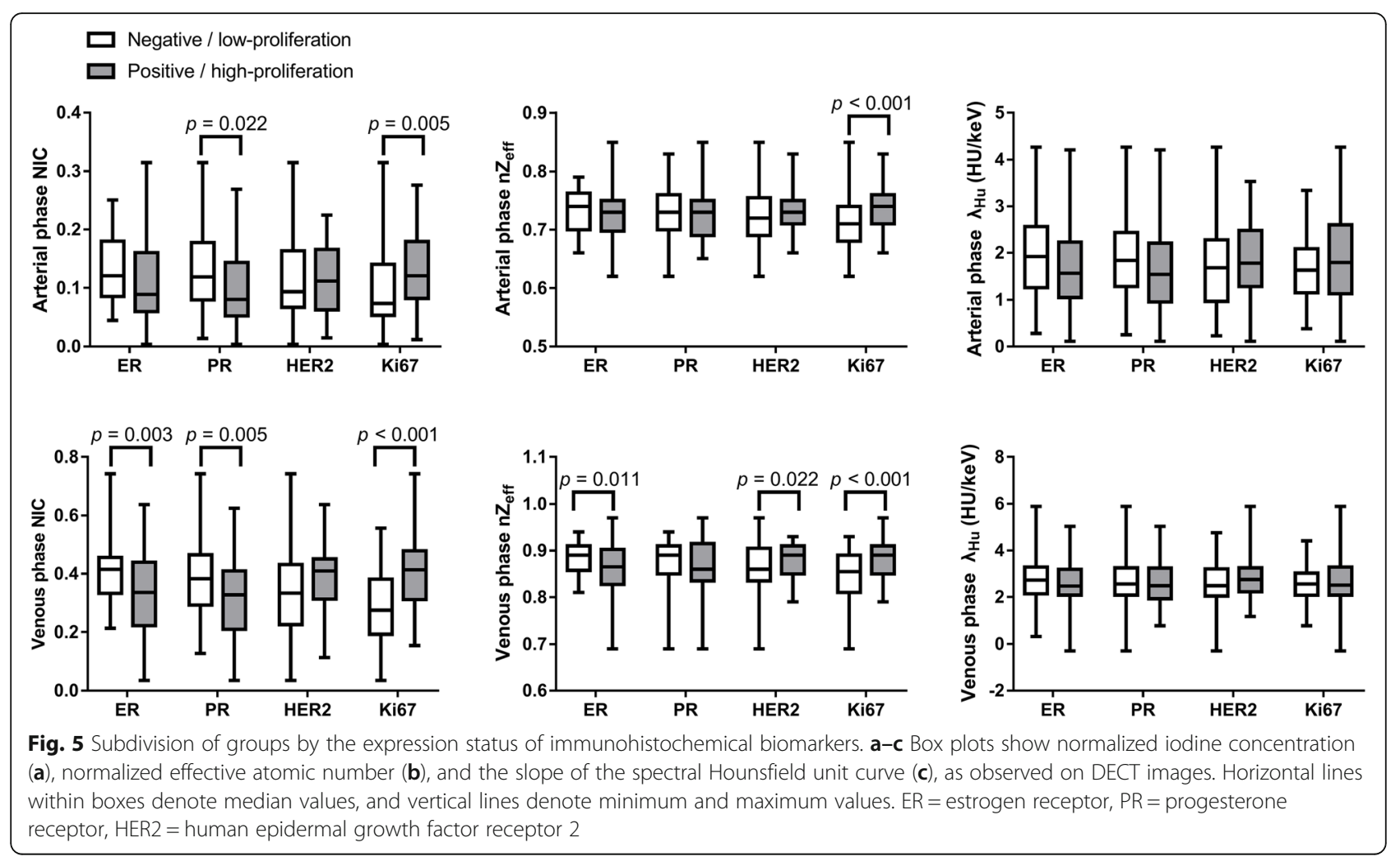

including mitosis and angiogenesis, resulting in an increase in the NIC value.

This study has several limitations. First, the number of cases was limited, and further studies with a relatively larger samples should be performed to validate the results of the present study through thresholding. Second, we focused only on invasive breast cancer. Further studies involving larger samples and wider spectra of breast lesions are warranted. Finally, direct comparisons between DECT quantitative parameters and histopathologic factors, such as cell density and microvessel density, were lacking. Therefore, the explanation for the

Table 3 Receiver Operating Characteristic Curve Analysis of DECT Quantitative Parameters for the DifferentialDiagnosis of Immunohistochemical Factors in Invasive Breast Cancer

\begin{tabular}{|c|c|c|c|c|c|}
\hline Parameter & AUC & Threshold of Parameter & Sensitivity (\%) & Specificity (\%) & Accuracy (\%) \\
\hline \multicolumn{6}{|l|}{ ER positive vs. negative } \\
\hline Venous phase NIC & $0.65[0.56,0.75]$ & 0.293 & $88.4(76 / 86)[79.2,94.0]$ & $41.2(14 / 34)[25.1,59.2]$ & $75.0(90 / 120)[66.5,81.9]$ \\
\hline Venous phase $n Z_{\text {eff }}$ & $0.60[0.49,0.70]$ & 0.87 & $70.9(61 / 86)[60.0,80.0]$ & $50.0(17 / 34)[32.8,67.2]$ & $65.0(78 / 120)[56.1,73.0]$ \\
\hline \multicolumn{6}{|l|}{ PR positive vs. negative } \\
\hline Arterial phase NIC & $0.63[0.53,0.73]$ & 0.082 & $75.5(40 / 53)[61.4,85.9]$ & $50.7(34 / 67)[38.4,61.0]$ & $61.7(74 / 120)[52.7,69.9]$ \\
\hline Venous phase NIC & $0.65[0.55,0.75]$ & 0.356 & $62.3(33 / 53)[47.9,74.9]$ & $62.7(42 / 67)[50.0,73.1]$ & $62.5(75 / 161)[53.6,70.7]$ \\
\hline \multicolumn{6}{|c|}{ HER2 positive vs. negative } \\
\hline Venous phase $n Z_{\text {eff }}$ & $0.59[0.49,0.69]$ & 0.87 & $70.2(33 / 47)[54.9,82.2]$ & $53.4(39 / 73)[41.4,65.0]$ & $60.0(72 / 120)[51.1,68.3]$ \\
\hline \multicolumn{6}{|c|}{ Ki67 low- vs. high-proliferation } \\
\hline Arterial phase NIC & $0.67[0.57,0.77]$ & 0.079 & $80.0(56 / 70)[68.4,88.3]$ & $54.0(27 / 50)[39.5,67.9]$ & $69.2(83 / 120)[60.4,76.8]$ \\
\hline Venous phase NIC & $0.75[0.67,0.84]$ & 0.281 & $88.6(62 / 70)[78.2,94.6]$ & $52.0(26 / 50)[37.6,66.1]$ & $73.3(88 / 120)[64.8,80.5]$ \\
\hline Arterial phase $\mathrm{n} Z_{\text {eff }}$ & $0.70[0.60,0.79]$ & 0.73 & $65.7(46 / 70)[53.3,76.4]$ & $62.0(31 / 50)[47.2,75.0]$ & $64.2(77 / 120)[55.3,72.2]$ \\
\hline Venous phase $n Z_{\text {eff }}$ & $0.67[0.57,0.77]$ & 0.86 & $74.3(52 / 70)[62.2,83.7]$ & $50.0(25 / 50)[35.7,64.3]$ & $64.2(77 / 120)[55.3,72.2]$ \\
\hline
\end{tabular}

Note-Data in parentheses are numerator/denominator; data in brackets are $95 \%$ confidential intervals. NIC normalized iodine concentration; $\lambda_{H u}$ slope of the spectral Hounsfield unit curve; $n Z_{\text {eff }}$ normalized effective atomic number; $H U$ Hounsfield unit; $A U C$ area under the curve 
Table 4 Correlations of DECT Quantitative Parameters with the Value of Immunohistochemical Biomarkers in Invasive Breast Cancer

\begin{tabular}{lll}
\hline Parameters & $\boldsymbol{r}$ value & $\boldsymbol{p}$ value \\
\hline Venous phase $\mathrm{NIC}$ and $\mathrm{ER}$ value & -0.265 & 0.002 \\
Venous phase $\mathrm{nZ}$ eff and $\mathrm{ER}$ value & -0.141 & 0.103 \\
Arterial phase $\mathrm{NIC}$ and $\mathrm{PR}$ value & -0.175 & 0.042 \\
Venous phase $\mathrm{NIC}$ and $\mathrm{PR}$ value & -0.239 & 0.005 \\
Venous phase $\mathrm{nZ}$ eff and $\mathrm{HER}$ 2 value & 0.112 & 0.194 \\
Arterial phase $\mathrm{NIC}$ and $\mathrm{Ki67}$ value & 0.315 & $<0.001$ \\
Venous phase $\mathrm{NIC}$ and Ki67 value & 0.490 & $<0.001$ \\
Arterial phase $\mathrm{nZ} \mathrm{Z}_{\text {eff }}$ and Ki67 value & 0.225 & 0.014 \\
Venous phase $\mathrm{nZ}$ eff and Ki67 value & 0.240 & 0.009 \\
\hline
\end{tabular}

Note. NIC normalized iodine concentration; $n Z_{\text {eff }}$ normalized effective atomic number; $E R$ estrogen receptor; $P R$ progesterone receptor; HER2 human epidermal growth factor receptor 2

relationship between DECT quantitative parameters and immunohistochemical biomarkers of invasive breast cancer was merely based on current findings from literature.

\section{Conclusions}

In conclusion, $\mathrm{NIC}$ and $\mathrm{nZ}_{\text {eff }}$ derived from DECT could be used to discriminate expression status and may associate with the values of immunohistochemical biomarkers of invasive breast cancer. In particular, the NIC value was associated with ER, PR, and Ki67 status, while the $\mathrm{nZ}_{\text {eff }}$ value was associated with ER, HER2 and Ki67 status.

\section{Abbreviations}

AUC: Area under the curve; ER: Estrogen receptor; HER2: Human epidermal growth factor receptor 2; HU: Hounsfield unit; keV: Kiloelectron volts; NIC: Normalized iodine concentration; $n Z_{\text {eff: }}$ Normalized effective atomic number; PR: Progesterone receptor; S: Standard deviation; $Z_{\text {eff: }} Z$ effective; $\lambda_{\text {Hu: }}$ Slope of the spectral Hounsfield unit curve

\section{Acknowledgements}

The authors thank all volunteers who participated in the study and the staff of the Department of Radiology, Chongqing University Cancer Hospital \& Chongqing Cancer Institute \& Chongqing Cancer Hospital in Chongqing, China, for their selfless and valuable assistance. We acknowledge the support of Xiaoyue Zhang from Siemens scientific research.

\section{Authors' contributions}

XW contributed to the conception and design of the study, data analysis and writing of the manuscript. DL contributed to performing the experiments and writing and revising the manuscript. $X Z$ and TY contributed to the data collection. LL and SJ contributed to the data analysis and interpretation of the data. JZ is the guarantor of this study and approved the version to be submitted. All authors accept responsibility for the integrity of the data and the accuracy of the data analysis. All authors read and approved the final manuscript.

\section{Funding}

This study has received funding by the National Natural Science Foundation of China (Grant No. 82071883), the combination projects of medicine and engineering of the Fundamental Research Funds for the Central Universities in 2019 (Project No. 2019CDYGYB008), the Chongqing key medical research project of combination of science and medicine (Grant No. 2019ZDXM007), and the 2019 SKY Imaging Research Fund of the Chinese International Medical Foundation (Project No. Z-2014-07-1912-10).

\section{Availability of data and materials}

The datasets used and/or analyzed during the current study are available from the corresponding author on reasonable request.

\section{Ethics approval and consent to participate}

This study was approved by Chongqing University Cancer Hospital institutional review board.

\section{Consent for publication}

All the authors have consented to the publication of this manuscript.

\section{Competing interests}

The authors declare that they have no competing interests.

Received: 3 March 2020 Accepted: 11 December 2020

Published online: 07 January 2021

\section{References}

1. Huo D, Hu H, Rhie SK, et al. Comparison of breast Cancer molecular features and survival by African and European ancestry in the Cancer genome atlas. JAMA Oncol. 2017:3:1654-62.

2. Metzger-Filho $\mathrm{O}$, Sun $\mathrm{Z}$, Viale $\mathrm{G}$, et al. Patterns of recurrence and outcome according to breast cancer subtypes in lymph node-negative disease: results from international breast cancer study group trials VIII and IX. J Clin Oncol. 2013;31:3083-90.

3. Sheri A, Dowsett M. Developments in Ki67 and other biomarkers for treatment decision making in breast cancer. Ann Oncol. 2012;23:x219-27.

4. Yerushalmi R, Woods R, Ravdin PM, Hayes MM, Gelmon KA. Ki67 in breast cancer: prognostic and predictive potential. Lancet Oncol. 2010;11:174-83.

5. Lee $Y$, Seo HS, Je BK, Kim SD, Oh HE. Benefit of dual-energy CT iodine overlay technique for T1-hyperintense brain lesion. Neurology. 2017;89: 1426-7.

6. Onishi S, Fujioka C, Kaichi Y, et al. Utility of dual-energy $C T$ for predicting the vascularity of meningiomas. Eur J Radiol. 2020;123:108790.

7. Li M, Zhang L, Tang W, et al. Quantitative features of dual-energy spectral computed tomography for solid lung adenocarcinoma with EGFR and KRAS mutations, and ALK rearrangement: a preliminary study. Transl Lung Cancer Res. 2019;8:401-12.

8. Dobbins JT 3rd, McAdams HP, Sabol JM, et al. Multi-institutional evaluation of digital Tomosynthesis, dual-energy radiography, and conventional chest radiography for the detection and Management of Pulmonary Nodules. Radiology. 2017;282:236-50.

9. Deniffel D, Sauter A, Dangelmaier J, Fingerle A, Rummeny EJ, Pfeiffer D. Differentiating intrapulmonary metastases from different primary tumors via quantitative dual-energy CT based iodine concentration and conventional CT attenuation. Eur J Radiol. 2019;111:6-13.

10. Kaltenbach B, Wichmann $J L$, Pfeifer $S$, et al. lodine quantification to distinguish hepatic neuroendocrine tumor metastasis from hepatocellular carcinoma at dual-source dual-energy liver CT. Eur J Radiol. 2018;105:20-4.

11. Gordic S, Puippe GD, Krauss B, et al. Correlation between dual-energy and perfusion CT in patients with hepatocellular carcinoma. Radiology. 2016;280:78-87.

12. Udare A, Walker D, Krishna $\mathrm{S}$, et al. Characterization of clear cell renal cell carcinoma and other renal tumors: evaluation of dual-energy CT using material-specific iodine and fat imaging. Eur Radiol. 2020;30:2091-102.

13. Sadoughi N, Krishna S, Macdonald DB, et al. Diagnostic accuracy of attenuation difference and iodine concentration thresholds at rapidKilovoltage-switching dual-energy $C T$ for detection of enhancement in renal masses. AJR Am J Roentgenol. 2019;213:619-25.

14. Li M, Zheng X, Li J, et al. Dual-energy computed tomography imaging of thyroid nodule specimens: comparison with pathologic findings. Investig Radiol. 2012;47:58-64.

15. Srinivasan A, Parker RA, Manjunathan A, Ibrahim M, Shah GV, Mukherji SK. Differentiation of benign and malignant neck pathologies: preliminary experience using spectral computed tomography. J Comput Assist Tomogr. 2013;37:666-72.

16. Tawfik AM, Razek AA, Kerl JM, Nour-Eldin NE, Bauer R, Vogl TJ. Comparison of dual-energy $C T$-derived iodine content and iodine overlay of normal, 
inflammatory and metastatic squamous cell carcinoma cervical lymph nodes. Eur Radiol. 2014;24:574-80.

17. Simons D, Kachelriess M, Schlemmer HP. Recent developments of dualenergy CT in oncology. Eur Radiol. 2014;24:930-9.

18. Weidner $\mathrm{N}$. The importance of tumor angiogenesis: the evidence continues to grow. Am J Clin Pathol. 2004;122:675-7.

19. Weidner N, Semple JP, Welch WR, Folkman J. Tumor angiogenesis and metastasis--correlation in invasive breast carcinoma. N Engl J Med. 1991;324:1-8.

20. Casiraghi M, De Pas T, Maisonneuve P, et al. A 10-year single-center experience on 708 lung metastasectomies: the evidence of the "international registry of lung metastases". J Thorac Oncol. 2011;6:1373-8.

21. Mahner S, Schirrmacher S, Brenner W, et al. Comparison between positron emission tomography using 2-[fluorine-18] fluoro-2-deoxy-D-glucose, conventional imaging and computed tomography for staging of breast cancer. Ann Oncol. 2008:19:1249-54.

22. Metin $\mathrm{Y}$, Metin NO, Ozdemir O, Tasci F, Kul S. The role of low keV virtual monochromatic imaging in increasing the conspicuity of primary breast cancer in dual-energy spectral thoracic $\mathrm{CT}$ examination for staging purposes. Acta Radiol. 2020;61:168-74.

23. Volterrani L, Gentili F, Fausto A, et al. Dual-energy CT for Locoregional staging of breast Cancer: preliminary results. Am J Roentgenol. 2020;214:707-14.

24. Goldhirsch A, Winer EP, Coates AS, et al. Personalizing the treatment of women with early breast cancer: highlights of the St Gallen international expert consensus on the primary therapy of early breast Cancer 2013. Ann Oncol. 2013;24:2206-23.

25. Tashima R, Nishimura R, Osako T, et al. Evaluation of an optimal cut-off point for the Ki-67 index as a prognostic factor in primary breast Cancer: a retrospective study. PLoS One. 2015;10:e0119565.

26. Zhang X, Zheng C, Yang Z, et al. Axillary sentinel lymph nodes in breast Cancer: quantitative evaluation at dual-energy CT. Radiology. 2018;289:337-46.

27. Park EK, Seo BK, Kwon M, et al. Low-dose perfusion computed tomography for breast Cancer to quantify tumor vascularity. Investig Radiol. 2019;54:273-81.

28. Ludovini V, Sidoni A, Pistola L, et al. Evaluation of the prognostic role of vascular endothelial growth factor and microvessel density in stages I and II breast cancer patients. Breast Cancer Res Treat. 2003;81:159-68.

29. Jarvinen TA, Pelto-Huikko M, Holli K, Isola J. Estrogen receptor beta is coexpressed with ERalpha and PR and associated with nodal status, grade, and proliferation rate in breast cancer. Am J Pathol. 2000;156:29-35.

30. Vazquez-Martin A, Colomer R, Menendez JA. Protein array technology to detect HER2 (erbB-2)-induced 'cytokine signature' in breast cancer. Eur J Cancer. 2007:43:1117-24.

31. Al-Najami I, Beets-Tan RG, Madsen G, Baatrup G. Dual-energy CT of rectal Cancer specimens: a CT-based method for Mesorectal lymph node characterization. Dis Colon Rectum. 2016;59:640-7.

32. Glazebrook KN, Doerge S, Leng S, et al. Ability of dual-energy CT to detect silicone gel breast implant rupture and nodal silicone spread. Am J Roentgenol. 2019;212:933-42.

33. Kontzoglou K, Palla V, Karaolanis G, et al. Correlation between Ki67 and breast cancer prognosis. Oncology. 2013;84:219-25.

34. Fan S, Li X, Zheng L, Hu D, Ren X, Ye Z. Correlations between the iodine concentrations from dual energy computed tomography and molecular markers Ki-67 and HIF-1alpha in rectal cancer: a preliminary study. Eur J Radiol. 2017;96:109-14.

35. Cheng SM, Ling W, Zhu J, Xu JR, Wu LM, Gong HX. Dual energy spectral CT imaging in the assessment of gastric Cancer and cell proliferation: a preliminary study. Sci Rep. 2018;8:17619.

\section{Publisher's Note}

Springer Nature remains neutral with regard to jurisdictional claims in published maps and institutional affiliations.

Ready to submit your research? Choose BMC and benefit from:

- fast, convenient online submission

- thorough peer review by experienced researchers in your field

- rapid publication on acceptance

- support for research data, including large and complex data types

- gold Open Access which fosters wider collaboration and increased citations

- maximum visibility for your research: over $100 \mathrm{M}$ website views per year

At BMC, research is always in progress.

Learn more biomedcentral.com/submissions 